\title{
ANAESTHETIC MANAGEMENT OF VOLUME CONTROLLED UNILATERAL LUNG LAVAGE*
}

\section{G. Douglas Blenkarn ${ }^{1}$, Charles F. Lanning ${ }^{1}$, and Johannes A. Kylstra ${ }^{2}$}

Conventional means to facilitate clearance of inspissated material obstructing gas exchange in the alveoli and finer airways of patients with alveolar proteinosis, asthma, and mucoviscidosis, are often not very effective. The mechanical removal of such materials by volume controlled unilateral lung lavage with saline has been of benefit in selected patients refractory to conventional therapy (particularly those with alveolar proteinosis or accidentally inhaled radioactive particles).$^{1-4}$

This report describes the anaesthetic and lavage techniques currently used in managing patients with alveolar proteinosis and mucoviscidosis and in whom lung lavage repeated at approximately six-month intervals has resulted in both subjective and objective improvements.

In 14 lavages in four different patients ( 10 lavages in two patients with alveolar proteinosis and four lavages in two patients with mucoviscidosis) certain physiologic responses to lung lavage, particularly those relating to oxygen transport, were measured quantitatively in an attempt to evaluate and to optimize anaesthetic and lavage techniques. The maintenance anaesthetic during lavage was selected randomly, so that each patient received light anaesthesia with ketamine/diazepam during one lavage and light halothane anaesthesia during lavage of the contralateral lung.

\section{Material and Methods}

All patients were admitted to the Clinical Research Unit approximately one week prior to the first lung lavage. During this time objective assessments of their disease were made and the appropriate conventional therapy was continued. On the morning prior to lung lavage patients were encouraged to raise secretions voluntarily or with the aid of IPPB treatments. All patients were premedicated with diazepam $10 \mathrm{mg}$ intramuscularly.

Prior to induction of anaesthesia, an intravenous infusion of glucose in lactated Ringer's solution was begun, a blood pressure cuff was applied, and EKG monitoring was commenced. After the administration of atropine $0.5 \mathrm{mg}$ intravenously, anaesthesia was induced with either diazepam $(0.15 \mathrm{mg} / \mathrm{Kg})$ and ketamine $(1.5$ $\mathrm{mg} / \mathrm{Kg}$ ) or thiopentone $(3.5 \mathrm{mg} / \mathrm{Kg})$. Endotracheal intubation was accomplished after topical application of hexylcaine (Cyclaine ${ }^{\circledR}$ ) 5 per cent to the larynx and trachea and the administration of 80 to $100 \mathrm{mg}$ of succinylcholine (Anectine). A small dose of non-depolarizing muscle relaxant, $1 \mathrm{mg}$ pancuronium (Pavulon ${ }^{\circledR}$ ) 1974

'Presented at the Canadian Anaesthetists' Society Meeting, St. John's, Newfoundland, June

From the Departments of Anaesthesiology, ${ }^{1}$ Medicine, ${ }^{2}$ Physiology and Pharmacology, ${ }^{2}$ Duke University Medical Center, Durham, N.C. 27710, U.S.A.

Present address: Dept. Anaesthesia, Dalhousie University, Halifax, Nova Scotia. 
was given prior to succinlycholine. Tracheal intubation at this point permitted further application of topical anaesthetic to the trachea, carina, and major bronchi and permitted suctioning of any secretions not removed voluntarily prior to induction. Anaesthesia was maintained with either ketamine $1.4 \mathrm{mg} / \mathrm{Kg}$ every $15 \mathrm{~min}$ utes or halothane 0.5 per cent. The anaesthetic technique (either halothane or ketamine) for the initial lavage was allocated randomly. The subsequent lavage, five to eight days later, was conducted using the alternate anaesthetic technique. All patients received 8 to $14 \mathrm{mg}$ pancuronium as required to prevent muscular responses and were ventilated throughout with 100 per cent oxygen using an Air Shields Ventimeter Ventilator and a semi-closed circuit with $\mathrm{CO}_{2}$ absorption. A 16-gauge plastic catheter was inserted into the brachial artery for intermittent sampling for blood gas determinations, continuous blood pressure monitoring and continuous $\mathrm{PO}_{2}$ monitoring using the IBC oxygen indwelling electrode. A central venous catheter was inserted for measurements of central venous pressure (CVP) and sampling for blood gas analysis (the position of the CVP catheter was confirmed radiographically following each lavage). All pressures (arterial, central venous, saline airway) were measured with Statham strain gauges with the hydrostatic reference position being the mid-chest and recorded with the EKG on a multi-channel recorder. A Carlens bronchospirometry catheter was then inserted in a method described by Lynch. ${ }^{5}$ Its position was confirmed by auscultation before and after clamping each channel. Total functional separation of the lungs was further confirmed by demonstrating absence of bubbling and the rising of the water level in a clear submerged tube connected to one channel of the Carlens catheter during ventilation of the contralateral lung. The opposite side was checked in an identical manner. Differential bronchospirometry was then performed to determine the oxygen uptake of each lung. Patients were then placed in a semilateral position so that the lung with the lower oxygen uptake was dependent. The dependent lung to be lavaged was then disconnected from the ventilator, passive expiration permitted to its FRC and then that channel of the Carlens catheter connected by rubber tubing to a calibrated reservoir containing a sterile 0.9 per cent sodium chloride solution (Urogate, Abbott Laboratories, Chicago, Ill.) at $38^{\circ} \mathrm{C}$. Saline was allowed to enter the dependent lung by gravity at a rate equal to the measured oxygen uptake previously determined by differential bronchospirometry and continued until a volume equal to the functional residual capacity (FRC) had been instilled. The FRC of the right lung was estimated to be 55 per cent, and that of the left lung 45 per cent of the FRC of both lungs, as measured prior to lung lavage by the helium dilution method. It was felt that by replacing the absorbed oxygen with saline at this rate, atelectasis, turbulence, and gas trapping would be minimized. Once FRC was reached, tidal volumes of $500 \mathrm{ml}$ of normal saline were alternately infused and drained by gravity until the effluent had become largely clear of airway casts, mucopurulent and proteinaceous material. The absorption of saline from the lavaged lung at a rate of approximately $350 \mathrm{ml} / \mathrm{hr}$ is associated with a lowering of the Pao.2, an increase in venous admixture and a lower airway pressure in the lavaged lung at a period of no flow. The continuous monitoring of these parameters permitted the volume of saline in the lung to be raised an appropriate amount so that tidal saline ventilations continued to occur 
in the upper ranges of the vital capacity. Up to 40 liters of saline were used during each lavage in this present series of patients. Airway pressures were measured at the proximal end of the Carlens tube in both liquid and gas channels and were monitored continuously. The other lung continued to be ventilated with 100 per cent $\mathrm{O}_{2}$. The ventilator was adjusted by assessing the effects on arterial blood pressure, central venous pressure, arterial blood gases, airway pressure and the length of expiration on chest auscultation. On completion of the lavage as much as possible of the liquid remaining in the lung was removed by a combination of postural drainage, chest percussion and suctioning following intermittent inflations of that lung with oxygen. (In no case can a volume of saline approximately cqual to the residual volume of the lavaged lung be removed from the lung immediately. Absorption, suctioning, and expectoration over the next two days resulted in clinical and radiological clearing of the residual lavage fluid.)

The Carlens catheter was then removed and replaced by a tracheal tube. All patients received intermittent positive pressure ventilation (IPPV) for one to five hours after lavage. During the first hour post-lavage and after reintubation of the trachea, IPPV facilitated the removal of residual saline by suction as it became displaced by oxygen introduced with the IPPV. IPPV may also have facilitated an increased rate of absorption of lavage fluid from the lung. Neuromuscular blockade was reversed in all patients prior to transfer to the recovery room.

Criteria for termination of IPPV and extubation were not rigid and were largely individualized. Assessment of minute volume, vital capacity, spontaneous breathing frequency, muscle strength, arterial blood gases, subjective and objective assessment of fatigue after T-tube breathing, level of cerebration, volume and rate of fluid suctioned from the endotracheal tube, volume of residual lavage fluid and history of respiratory performance following previous lavages were all employed as criteria for weaning from the ventilator and tracheal tube. Following extubation, the patients were closely observed in an intensive care area, with measurement of arterial blood gases and were given supplemental oxygen for the next 24 hours as required. The contralateral lung was lavaged five to seven days later when subjective and objective pulmonary performance had returned to prelavage levels or better and if the clinical course post-lavage had been otherwise uneventful.

Brachial artery and central venous blood (svc) was sampled simultaneously at the following specific times: (1) more than 40 minutes after induction of anaesthesia, after ventilation with 100 per cent oxygen and prior to lung lavage, (2) at least 20 minutes after commencement of tidal lavage and 1 minute after instillation of a tidal volume of $500 \mathrm{ml}$ of saline (FRC +500 or inspiration), (3) at least 20 minutes after commencement of tidal lung lavage and 1 minute after expiration of the $500 \mathrm{ml}$ tidal volume (FRC or expiration). The results reported are means of two samples taken at each of these three times. Blood samples were drawn into heparinized glass syringes, capped immediately and stored in ice until they were analyzed. Samples were analyzed for $\mathrm{Po}_{2}, \mathrm{Pco}_{2}$, and $\mathrm{pH}$ by Instrumentation Laboratory blood gas electrodes and by a Radiometer $\mathrm{pH}$ electrode within 30 minutes after the time of sampling. From these direct measurements, $\left(\mathrm{pH}, \mathrm{Po}_{2}, \mathrm{PCO}_{2}\right.$, 
haemoglobin and temperature) oxygen content of arterial and venous blood was computed according to Kelman. ${ }^{6}$

\section{Results}

Table I summarizes and compares mean measured values of blood gases and computed oxygen contents during ketamine vs. halothane maintenance anaesthesia. Although data was collected on 14 different lavages in four patients, two patients were studied on more than one occasion and accordingly means were derived for their data prior to paired $\mathrm{T}$-test analysis. With respect to anaesthetic technique, no significant differences were observed in blood gases, computed oxygen contents (Table I), heart rate, systolic and diastolic blood pressure between ketamine or halothane anaesthesia (Table II). Table I showed that the patients' acid base status was maintained within normal ranges throughout the duration of the study. Table III summarizes blood gas and oxygen content data as they were altered by the state of lung filling with saline. Data for each of the four subjects was analyzed by paired T-test. Unilateral lung lavage predictably impaired arterial oxygenation, being more profound after emptying to FRC (expiration). The physiological shunt was double the control values during expiration. During lung lavage arterial oxygenation was maximal and physiological shunting minimal following filling of the lung with $500 \mathrm{ml}$ tidal volume (inspiration or FRC $+500)$. The oxygen content difference between arterial and superior vena caval (svc) blood increased significantly from $3.01 \pm 0.42$ during the control period to $4.40 \pm 0.35(\mathrm{p}<0.05)$ at $\mathrm{FRC}$ and increased further to $4.67 \pm 0.53$ at FRC $+500(\mathrm{p}<0.05)$.

\section{Discussion}

Since the minute volume was not altered from 20 minutes prior to the initial sampling period through to the end of the lavage and since during this time there were no significant changes in $\mathrm{PaCO}_{2}$, we may assume that the oxygen consumption $\left(\dot{V}_{\mathrm{O}_{2}}\right)$ remained relatively constant throughout the period of anaesthesia and lavage. In the presence of a constant minute volume, any significant change in $\dot{\mathrm{V}}_{2}$ and $\dot{\mathrm{V}} \mathrm{CO}_{2}$ would have been reflected by a parallel increase in $\mathrm{PaCO}_{2}$.

Blood was sampled from the superior vena cava close to or at its junction with the right atrium, rather than from the pulmonary artery. This was confirmed in every case by post-lavage radiographs. Consquently, the blood gases measured were not truly mixed venous blood and for this reason it was not possible to compute cardiac output. However, changes in a- $v_{\text {swe }}$ differences for oxygen (assuming that $\dot{V} o_{2}$ was constant) do reflect the degrees of change in cardiac output and computed shunt due to the state of lung filling. Lastly, the authors acknowledge that these measurements were made in non-steady states with respect to cardio-respiratory alterations induced by changes in volume of saline in the lung. It might be suggested that a longer period of time should have elapsed prior to evaluating changes induced by inspiration (FRC +500$)$ and expiration (FRC). However, this was not consistent with patient safety nor with the actual alterations in haemo- 


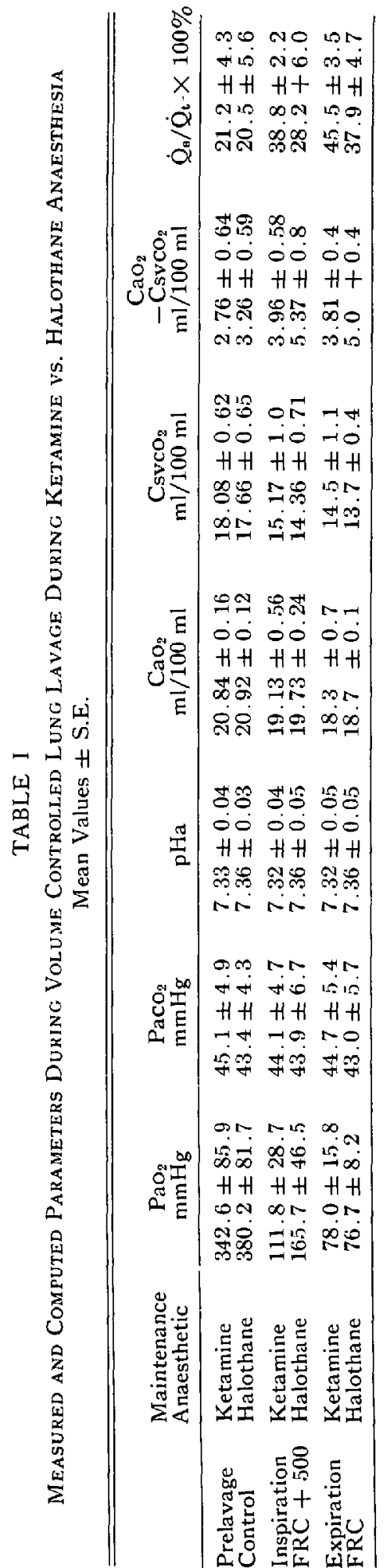


TABLE II

Arterial Blood Pressure and Heart Rate During Volume Controlled Lung Lavage: Ketamine vs. Halothane Mean Values \pm S.E.

\begin{tabular}{lccc}
\hline Maintenance & $\begin{array}{c}\text { Systolic } \\
\text { Blood } \\
\text { Pressure } \\
\text { mmHg }\end{array}$ & $\begin{array}{c}\text { Diastolic } \\
\text { Blood } \\
\text { Pressure } \\
\text { mmHg }\end{array}$ & $\begin{array}{c}\text { Heart Rate } \\
\text { Beats/min }\end{array}$ \\
\hline $\begin{array}{l}\text { Ketamine } \\
\text { Halothane }\end{array}$ & $130 \pm 9.3$ & $80.0 \pm 6.8$ & $121.1 \pm 5.8$ \\
\hline
\end{tabular}

dynamics and blood gas transport that occur during this procedure when performed for therapeutic purposes.

While recognizing the limitations which these factors impose upon the conclusions we feel that the following generalizing statements are justified: (1) the smaller a- $\mathrm{v}_{\mathrm{s}} \mathrm{O}^{2}$ difference observed in the control period before lavage would suggest that the cardiac output was greater than in the basal state. Elevation in blood pressure and heart rate relative to the pre-anaesthetic state is consistent with this conclusion and this increase in cardiac output prior to lavage probably represents the cardiovascular response to bronchial intubation in the presence of light anaesthesia, (2) filling one lung with saline resulted in a large reduction in cardiac output relative to the control period as by a 55 per cent increase in Caom$\mathrm{CsvcO}_{2}$ at $\mathrm{FRC}$ and 46 per cent in $\mathrm{CaO}_{2}-\mathrm{Csvco}_{2}$ at $\mathrm{FRC}+500$. These findings suggest that the filling of one lung with saline and the simultaneous intermitten positive pressure ventilation of the contralateral lung impose significant impairment of venous return and consequently reduced cardiac output relative to control conditions. While these values approximate those found in normal resting man, it must be appreciated that these are not true mixed venous samples as they do not include the more desaturated myocardial venous return. Consequently, cardiac output appeared to be less than basal during the lavage period. Rogers, et al. have reported an a-v oxygen content difference of $5.12 \pm 1.06$ per $100 \mathrm{ml}$ (mean \pm S.D.) the magnitude of which they attributed directly to the depth of anaesthesia and not to an impairment in venous return. We found a small significant difference in $\mathrm{CaO}_{2}-\mathrm{CsvcO}_{2}$ at FRC (expiration) vs. FRC +500 (inspiration). Increased physiologic shunting and decreasing oxygenation of arterial blood observed after holding the lung at expiration or FRC for $1 \mathrm{~min}$, precluded extending this period of observation further. One would logically anticipate that the additional impairment of venous return and cardiac output at FRC +500 (inspiration) would be reflected in an increased $\mathrm{CaO}_{2}-\mathrm{CsvcO}_{2}$ had the period of observation at inspiration been extended.

After assuming an a-vO $\mathrm{O}_{2}$ difference of 4.5 vol, $\%$, Wasserman, et al. reported a reduction in venous admixture during lung filling and the development of marked hypoxaemia in a patient undergoing lung lavage for alveolar proteinosis. ${ }^{7}$ Later, Smith reported similar findings and suggested that increased pressure in the liquid filled lungs resulted in a greater flow to the $\mathrm{O}_{2}$ ventilated contralateral lung. ${ }^{8}$ Rogers confirmed these previous observations and interpreted these findings in terms of the "vascular waterfall" described by Permutt."10 Our findings are in 


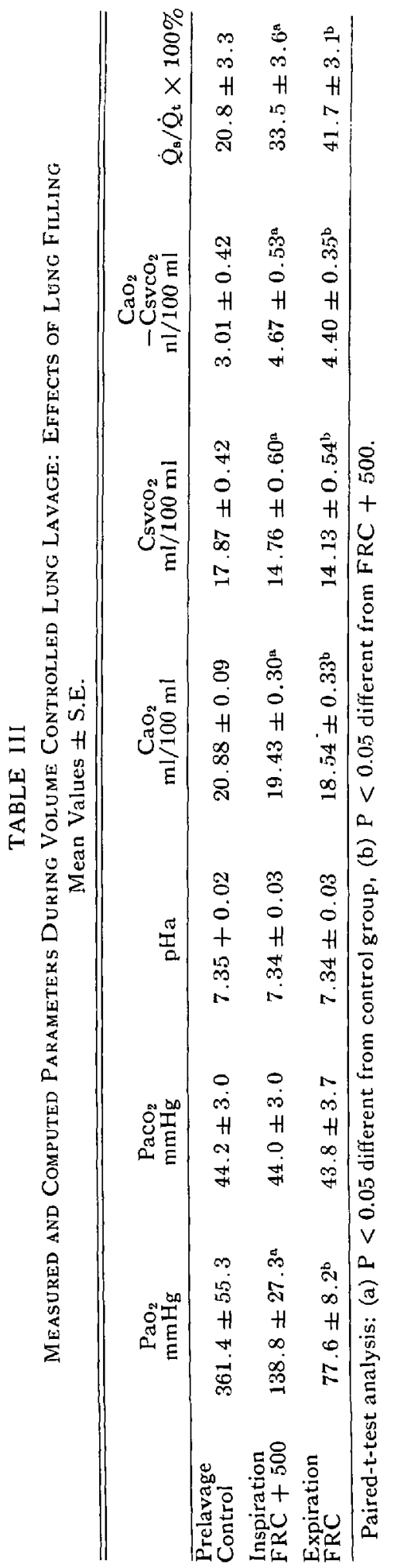


agreement with those of previous investigators as the calculated physiologic shunt increased from a control value of $20.8 \pm 3.3$ per cent to $33.5 \pm 3.6$ per cent at FRC +500 and to $41.7 \pm 3.1$ per cent at FRC.

\section{SUMMARY}

Light general anaesthesia combined with marked muscle paralysis can be used as the procedure while unpleasant and terrifying is not painful nor surgically stimulating. In addition the airway is well anaesthetized topically. Paralysis permits maximal control over the patient and the maintenance of position of the Carlens tube, in a situation where movement or coughing might be dangerous. Paralysis also maximizes lung-thorax compliance, reduces $\mathrm{O}_{2}$ consumption and permits lavage under light anaesthesia. The choice of maintenance anaesthetic appeared to be a negligible factor in the management of these patients. With the doses of ketamine employed, post-lavage CNS depression did not delay weaning and extubation. Dreaming, hallucinations and emergence delirium related to ketamine were not reported nor observed. The absence of these phenomena was probably related to the use of diazepam before and immediately after the lavage but prior to weaning from the respiratory support as suggested by Coppel, et al. ${ }^{11}$ In our opinion either ketamine or halothane employed in these doses are suitable maintenance anaesthetics. The use of ketamine does avoid the controversial administration of two halothane anesthetics in close sequence. Of most importance, light anaesthesia with minimal cardiac and vasomotor depression facilitates maximal cardiovascular reactivity (as indicated by the maintenance of systemic pressure and tachycardia) in this setting of marked physical impediment to venous return which is imposed by the saline filled lung and vigorous ventilation of the contralateral lung. ${ }^{12}$

The lavage is conducted in the upper range of the vital capacity and the continuous assessment of $\mathrm{PaO}_{2}$ is vital, to detect and to control the large fluctuations induced by the lavage and the consequent distribution of pulmonary blood flow.

Lavage in the upper portion of the vital capacity maximizes the liquid expiratory flow rate, as the lung-thorax recoil remained high. ${ }^{13}$ Blood flow to the lavaged side is minimized so that a higher arterial oxygen content and $\mathrm{PaO}_{2}$ is achieved. The largest reduction of perfusion to the liquid filled lung is not obtained until lung filling has exceeded the FRC. In our experience this is best determined by: (1) prior knowledge of the FRC, so that the lung can be filled initially to this volume, (2) filling the lung until one can demonstrate a rise in $\mathrm{PaO}_{2}$ coincident with each $500 \mathrm{ml}$ tidal volume of saline, and (3) filling the lung until one can demonstrate a rise in airway pressure coincident with each $500 \mathrm{ml}$ tidal volume of saline. Overfilling the lavaged lung would predictably reduce shunting or venous admixture even further; however, the danger of mechanical damage associated with overdistension precludes this maneuver. Prior knowledge of the total lung capacity and continuous monitoring of airway pressure in the lavaged lung at the time of no flow has been found useful in preventing overdistension.

\section{RÉSUMÉ}

Un lavage pulmonaire étant une expérience à la fois désagréable et terrifiante, 
même si en soi elle n'est pas douloureuse, une anesthésie générale légère avec relâchement musculaire marqué et anesthésie topique des voies aériennes représente une technique satisfaisante.

Dans une situation où les mouvements ou la toux peuvent être dangereux, la paralysie du malade permet un contrôle complet du patient et le maintien en place du tube de Carlens. Elle rend également possible un lavage sous anesthésie légère, réduit la consommation d'oxygène et assure une compliance poumonthorax optimale.

Le choix de l'anesthésique de maintien nous apparaît d'ordre secondaire. Si la Kétamine est utilisée ( $1.4 \mathrm{mg} /$ kilo aux $15 \mathrm{~min}$ ), la dépression du système nerveux central ne retarde pas le sevrage du ventilateur et l'extubation. Egalement nous n'avons pas relevé chez nos malades d'hallucinations ou de délire, ce que nous attribuons comme Coppel et Coll. à l'administration de Diazepam avant le lavage et avant le sevrage du respirateur.

Nous sommes d'opinion que la Kétamine et l'Halothane sont tous deux des agents recommandables dans ces cas. L'emploi de Kétamine permet d'éviter les administrations répétées à court intervalle d'Halothane.

Le remplissage d'un poumon avec du soluté physiologique et la ventilation vigoureuse concomittante de l'autre poumon réduisant tous les deux la retour veineux, il est d'autant plus important d'employer un agent anesthésique qui respecte le système cardio-vasculaire.

Le lavage est effectué à des volumes voisins de la capacité vitale. Il est important de suivre continuellement la $\mathrm{Pa}_{\mathrm{O}_{2}}$ qui fluctue beaucoup (remplissage liquidien d'un poumon et modifications de la perfusion pulmonaire). Un remplissage liquidien à la limite supérieure de la capacité vitale facilite l'évacuation "expiratoire" du liquide je lavage. Aussi la circulation dans un poumon "rempli" est-elle au minimum ce qui diminue le shunting et contribue à une meilleure oxygénation. L'on n'obtient une réduction maximale de la perfusion dans le poumon lavé que lorsque le volume de remplissage dépasse la capacité résiduelle fonctionnelle.

Nous croyons en conséquence que l'on devrait : (1) Obtenir une mesure préalable de la $\mathrm{FRC}$ ce qui permet de remplir le poumon à ce volume dans un premier temps. (2) Continuer à emplir et rincer le poumon de a volumes courants " de $500 \mathrm{ml}$ jusqu'à amélioration de la $\mathrm{Pa}_{\mathrm{O}_{2}}$. (3) Continuer le remplissage jusqu’à l'apparition d'une élévation de la pression des voies aériennes. Le surremplissage du poumon lavé, s'il contribue à une diminution du shunting comporte quand même certains risques de dommages mécaniques. La mesure préalable de la capacité pulmonaire totale et le monitoring continue des pressions dans les voies aériennes du poumon lavé, aide à prévenir la surdistension.

\section{REFERENCES}

1. Kylstra, J.A., Rausch, D.C., Hall, K.D., \& Spock, A. Volume-controlled lung lavage in the treatment of asthma, bronchiectasis, and mucoviscidosis. Am. Rev. of Respiratory Disease 103: 651-665 (1971).

2. Ramirez, R.J. Bronchopulmonary lavage. New techniques and observations. Dis. Chest 50: 581-588 (1966).

3. Rocens, R.M. \& TANTum, K.R. Bronchopulmonary lavage. A "new" approach to old problems. Medical Clinics of North America 54: 755-771 (1970). 
4. McClellan, R.O., Boyd, H.A., Benjamin, S.A., et al. Bronchopulmonary lavage and DTPA treatment of an accident inhalation $239 \mathrm{Pu}$ exposure case, Fission Product Inhalation Program. Annual Report 287-303 (1972).

5. Lynch, C.C. \& Ferann, F. Endobronchial anesthesia. Anesthiology 18: 138-140 (1957).

6. Kelman, G.R. Digital computer subroutine for the conversion of oxygen tension into saturation. J. Appl. Physiol. 24 (4) 1375-1376 (1966).

7. Wasserman, K., Blank, N., \& Fletcher, G. Lung lavage (alveolar washing) in alveolar proteinosis. Am. J. Med. 44: 611-617 (1968).

8. Smith, J.D., Mrllen, J.E., SAFAR, P., et al. Intrathoracic pressure, pulmonary vascular pressures and gas exchange during pulmonary lavage. Anesthesiology 33: 401-405 (1970).

9. Rogers, R.M., Szidon, J.P., Shelburne, G., Neich, J.D., Shuman, J.F., \& Tantum, K. Hemodynamic response of the pulmonary circulation to bronchopulmonary lavage in man. New England Journal of Med. 286: 1230-1233 (1972).

10. Permutt, S. \& Riley, R.L. Hemodynamics of collapsible vessels with tone: the vascular waterfall. J. Appl. Physiol. 18: 924-932 (1963).

11. Coppel, D., Bovill, J.G., \& DundeE, J.W. The taming of ketamine. Anaesthesia 28: 293-296 (1973).

12. Price, H.L., ConNer, E.H., \& Dripps, R.D. Some respiratory and circulatory effects of mechanical respirators. J. Appl. Physiol. 6: 517-530 (1954).

13. Mead, J., Turner, J.M., Macklem, P.T., \& Litrle, J.B. Significance of the relationship between lung recoil and maximum expiratory flow. J. Appl. Physiol. 22: 95-108 (1967). 